\title{
Perspectives on whole-organ assembly: moving toward transplantation on demand
}

\section{Alejandro Soto-Gutierrez, ${ }^{1,2,3,4,5}$ Jason A. Wertheim, $6,7,8,9$ Harald C. Ott, ${ }^{10}$ and Thomas W. Gilbert ${ }^{11}$}

\author{
1Department of Pathology, ${ }^{2}$ Center for Innovative Regenerative Therapies, ${ }^{3}$ Department of Surgery, \\ Transplantation Section of Children's Hospital of Pittsburgh, ${ }^{4}$ McGowan Institute for Regenerative Medicine, and ${ }^{5}$ Thomas E. Starzl Transplantation Institute, \\ University of Pittsburgh, Pittsburgh, Pennsylvania, USA. ${ }^{6}$ Comprehensive Transplant Center, ${ }^{7}$ Department of Surgery, and \\ ${ }^{8}$ Institute for BioNanotechnology in Medicine, Northwestern University, Chicago, Illinois, USA. ${ }^{9}$ Chemistry of Life Processes Institute, \\ Northwestern University, Evanston, Illinois, USA. ${ }^{10}$ Department of Surgery, Division of Thoracic Surgery, Massachusetts General Hospital, \\ Harvard Medical School, Boston, Massachusetts, USA. ${ }^{11}$ McGowan Institute for Regenerative Medicine, Departments of Surgery, \\ Cardiothoracic Surgery, and Bioengineering, University of Pittsburgh, Pittsburgh, Pennsylvania, USA.
}

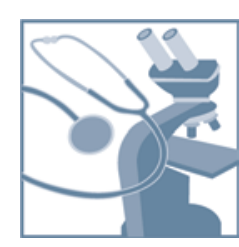

There is an ever-growing demand for transplantable organs to replace acute and chronically damaged tissues. This demand cannot be met by the currently available donor organs. Efforts to provide an alternative source have led to the development of organ engineering, a discipline that combines cell biology, tissue engineering, and cell/organ transplantation. Over the last several years, engineered organs have been implanted into rodent recipients and have shown modest function. In this article, we summarize the most recent advances in this field and provide a perspective on the challenges of translating this promising new technology into a proven regenerative therapy.

\section{Introduction}

Solid organ transplantation is the therapy of choice for nonreversible acute and chronic organ failure from almost any cause. The success of transplantation, which is based on advances in immunosuppressive medications, refined surgical techniques, and improved management of patients with chronic disease, is reflected by the continually increasing number of patients alive with a functioning transplanted organ. For example, in 1993 there were 39,513 patients alive with a functioning renal transplant in the United States and 144,200 were alive in 2009 (http://optn.transplant.hrsa.gov) $(1,2)$.

The number of life-saving transplant procedures is driven by the scarcity of usable donor organs rather than patient demand. Organ Procurement and Transplantation Network data from May 2012 showed that over 114,420 patients were waiting for organs in the United States, representing more than a four-fold increase in the past 20 years $(1,2)$. During that same interval, deceased and living donors increased only two fold and matched the increase in transplantation procedures (15,756 procedures in 1991 and 28,537 procedures in 2011) $(1,2)$. Despite exhaustive efforts to promote organ donation, the national organ waiting list for patients needing a solid organ transplant has never declined.

Donor organs are rationed based upon the principles of justice and utility due to their limited supply. However, distribution varies according to the organ and the availability of extracorporeal support devices such as dialysis and cardiac assist machines. For instance, priority for liver transplantation, for which no extracorporeal support device has been approved, is largely determined by the model for end-stage liver disease (3), a stratification system that prioritizes patients to receive liver offers based upon their degree of liver dysfunction. Donor lungs are distributed based upon a

Conflict of interest: Thomas W. Gilbert served on the scientific advisory board of ACell Inc. during the writing of this manuscript. Since acceptance of the manuscript, he became the Vice President of Research and Development at ACell Inc., which commercializes ECM from porcine urinary bladder for clinical use in tissue repair. Jason A. Wertheim reports expenses paid by Cellular Dynamics International for research-related travel that is unrelated to the preparation of this manuscript.

Citation for this article: J Clin Invest. 2012;122(11):3817-3823. doi:10.1172/JCI61974. patient's lung allocation score, which is derived from diagnosis, comorbidities, and functional parameters. Other organs are given to patients who have accrued the longest time on the waiting list.

The development of alternative sources of donor organs would change the paradigm of organ transplantation. One popular method to develop bioartificial tissues involves the decellularization of target organs, seeding with appropriate cell types, and maturation of the neo-organ in a physiologically appropriate bioreactor (4-9). Developing tissue-engineered organs could reduce waiting list mortality because of faster production of bioartificial organs. Further, a robust engineered organ supply would allow transplantation at a time when patients are healthier.

Here, we describe the current state of the art in organ engineering and provide perspective on the biological and engineering challenges that must be overcome to realize bioartificial organs. We highlight the need for appropriate sources of scaffolds and cells and to advance the understanding of neo-tissue development (Figure 1).

\section{Organ engineering}

The earliest roots of organ engineering go back to the 1950s when the concept of seeding cells onto 3D constructs was first conceived (10). In terms of biologic tissue constructs, the 1970 s brought forth technologies related to solubilization and repolymerization of collagen gels with cells to assemble "tissue equivalents" (11). Isolation and decellularization of organ-specific ECM was reported throughout the 1970s and 1980s, as it was recognized that ECM provided more than a simple structure upon which cells could attach and move (12-16). The term "tissue engineering" was introduced in 1985 by Y.C. Fung and popularized in 1993 by Langer and Vacanti (17). Tissue engineering was defined as an interdisciplinary field that combined the technologies of biology and engineering to develop tissues to replace damaged organs. The earliest engineered tissues, developed in the 1990s, were thin, planar tissues, primarily dermis (18). Also in the 1990s, decellularized tissues were developed into medical devices that could modulate tissue repair without antigenicity. These scaffolds served as adequate surgical meshes in the case of acellular dermal allografts (19), while xenogeneic scaf- 


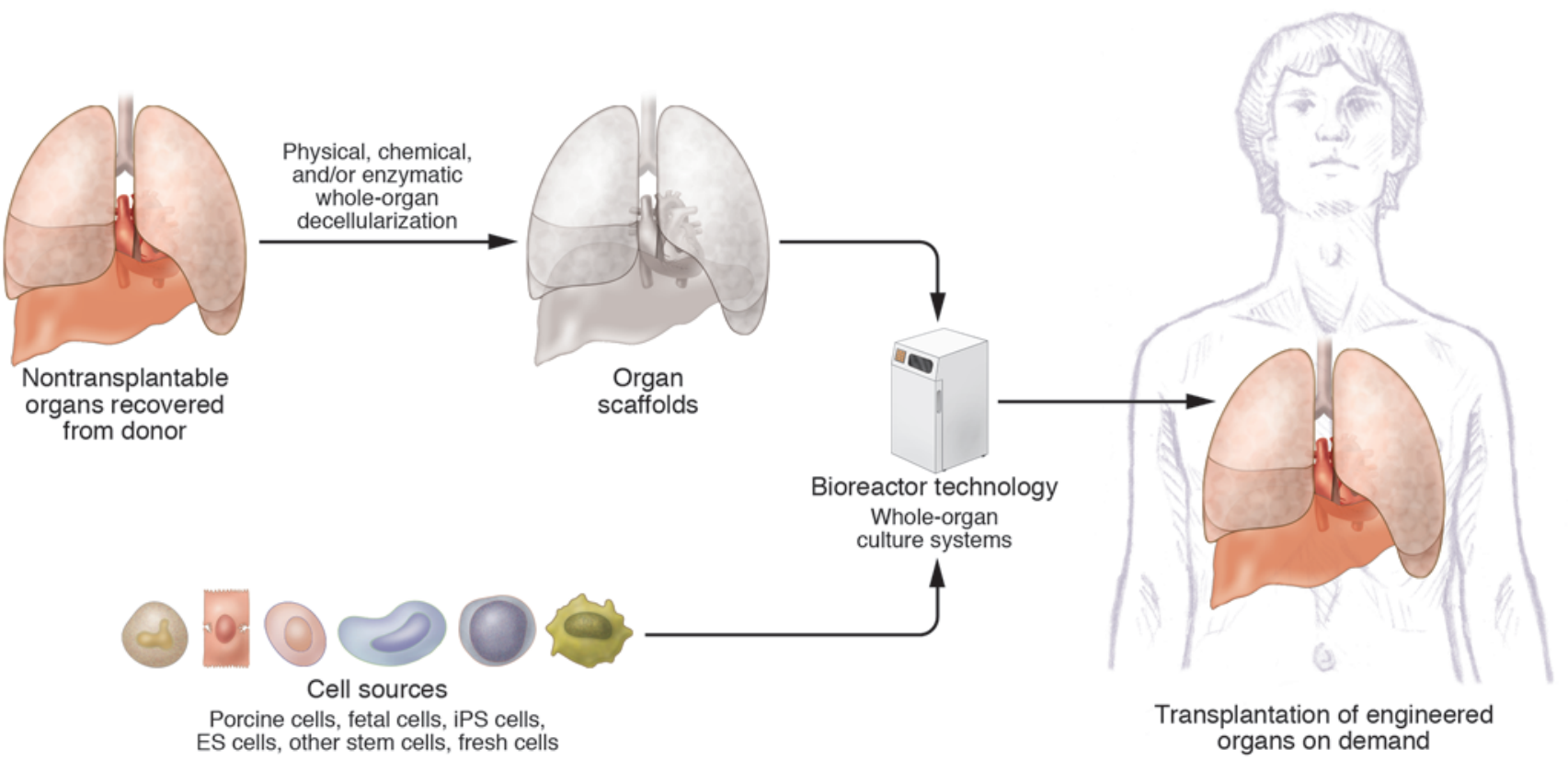

Figure 1

Schematic representation of the paradigm of regenerative medicine showing the conversion of whole-organ decellularization with cellular developmental biology and biomedical engineering. Cells from nontransplantable donor organs or animal sources are removed using various chemical and enzymatic agents, usually including detergents and trypsin. Candidate cells used to repopulate these organ matrices range in developmental stages from pluripotent stem cells to mature, freshly isolated cells - though the optimal cell source for this purpose has yet to be identified. The assemblage of cells and organ scaffolds are cultured together in whole-organ bioreactors that recapitulate the body's natural milieu, including fluid pressure, $\mathrm{pH}$, dissolved oxygen, and growth factors for future clinical transplantation, or as a platform to conduct whole-organ biological and pharmacological studies.

folds derived from porcine small intestinal submucosa (SIS) promoted site-appropriate tissue remodeling (20). More recently, the approaches of cellularized synthetic and decellularized scaffolds have extended to more complex tissues with early clinical experience for the urinary bladder and trachea (21-23).

The concept of perfusion decellularization of an organ was proposed and realized within the last decade (4). This approach uses the vascular bed as an efficient means to decellularize the intact organ by reducing the diffusion distance required for decellularization agents to reach the cells and facilitating removal of the cellular material from the tissue by convective transport. Rodent hearts were perfused with SDS and Triton X-100 in a retrograde manner through the ascending aorta and produced acellular 3D scaffolds capable of supporting the growth of donor cells in a flow bioreactor (4). This technique allowed creation of acellular scaffolds that retain vascular channels through which scaffolds are recellularized and cell growth is supported with perfusion of media. Tissue-engineered livers and lungs have been decellularized using similar strategies to reduce the diffusion distance (e.g., bile duct in liver, intratracheal instillation in lungs). Although the results thus far have shown only limited function over short periods of implantation into recipient rodents, this achievement is a significant step toward an eventual therapeutic modality for human patients $(4,24-29)$. Scale-up strategies are currently being developed for large (porcine, primate, human) organs (30-32).

\section{Organ scaffold sourcing}

There are a variety of potential sources for scaffolds, each of which has advantages and disadvantages. A sizeable supply of donated human organs that are not usable for transplantation could be "rehabilitated" using perfusion decellularization. In the United States, approximately $60 \%$ of organs from eligible donors were used for human transplantation and the remainder was discarded, (33) some due to poor organ parenchyma quality that may be improved using organ engineering. An estimated $25 \%$ of the total deaths in the United States (approximately 500,000 people per year) are acute deaths, before senility, and without incurable disease or organ impairment (34). Theoretically, all organs harvested within a reasonable time frame postmortem (i.e., before proteolysis at approximately 4 to 6 hours) (35) could serve as potential donors for organ decellularization. The current practice of using organs for transplantation from donors after cardiac death limits organ recovery to 30 to 60 minutes after cardiac cessation. The added time in which the matrix of decellularized organs may be viable could allow potential donors to be identified after their death and increase the number of organs available for donation.

An alternative, ample supply of organs could come from animals. To date, biologic meshes from porcine, bovine, and equine sources have been successfully implanted into humans. The tissues are obtained from pathogen-free herds of animals, and processing eliminates most known pathogens. Most of the xenogeneic scaffolds are chemically cross-linked to obscure antigens that promote rejection, although decellularization protocols likely renders this process unnecessary. The majority of proteins in ECM are highly conserved among species (5). One antigen that is retained at low levels is galactosyl- $\alpha(1,3)$ galactose $(\mathrm{Gal})$, a cell surface epitope that is absent in primates and humans and is known to cause acute rejection in whole-organ xenografts. The Gal epitope prompts a 
transient immune response that is not complement activating (36). This immune activation does not appear to alter the host response to the scaffolds (37). If necessary, further reduction of the Gal epitope can be achieved by enzymatic cleavage during processing $(38,39)$ or by obtaining tissues from genetically modified pigs that lack the Gal epitope $(37,40)$. The attractive aspect of xenogeneic organs as a source of ECM is the availability of organs and the potential to secure healthy, pathogen-free tissue.

Regardless of the source, issues such as storage life and preservation are critical. A recent report showed that decellularized tracheas retain their properties for up to a year after decellularization (41). Similar studies will be necessary for other organs to determine how storage impacts the ECM and to optimize recellularization long after organ recovery when sufficient recipient cells are prepared to reseed the organ scaffold.

\section{Organ decellularization}

The objective of the decellularization process is to maximize removal of cellular material from the tissue, while minimizing the damage and loss of the target ECM components. Care must be taken to develop appropriate decellularization protocols for each tissue and to perform appropriate quality control. The mechanism of action and effects of different tissue decellularization agents have been systematically reviewed elsewhere $(5,42)$. The criteria that define a successful decellularization process are poorly understood. Only recently have objective criteria for assessing the efficacy of decellularization been proposed, including (a) the absence of nuclei based upon histologic staining with hematoxylin and eosin and DAPI, (b) quantitative measurement of DNA at less than $50 \mathrm{ng} / \mathrm{mg}$ dry tissue weight, and (c) DNA fragment size below 200 bp (42). These criteria were based primarily on studies of ECM from porcine SIS and urinary bladder matrix (UBM), and their relevance to decellularized whole organs has not been explicitly tested (43). Furthermore, recent reports suggest that these criteria are insufficient to predict optimal decellularization. A study performed with UBM showed that increased DNA content had less impact on host response to the material than the processing method (44). Because the decellularization process of vascularized whole organs differs greatly from the process to decellularize a planar tissue used as a surgical mesh, the effect of residual cell content may vary, either to the benefit or detriment of the outcome.

DNA is often quantified to determine decellularization efficacy because it is an easily detectable marker that suggests that other cellular components, such as membranes, proteins, and antigens, were also removed (45). The persistence of intracellular proteins and cell surface antigens has been largely unexplored, with the exception of the Gal epitope in SIS and dermis $(36,39)$ as well as actin and myosin in decellularized lungs $(46,47)$.

Decellularization agents, particularly those used for decellularization of complex tissues and organs, solubilize ECM components to remove them from the tissue while also disrupting the structure of retained molecules $(5,42,43)$. Although tissue decellularization has been extensively reported in the literature, the protocols include a variety of different chemicals, and few systematic studies have compared the effects of isolated decellularization agents on tissues. In particular, little is known about how decellularization alters the micromechanics of ECM, an important consideration given the influence of matrix stiffness on stem cell differentiation and morphogenesis $(48,49)$. Decellularization can disrupt collagen structure and activate matrix metalloproteases (46), both of which could decrease the scaffold stiffness and accelerate its degradation. Furthermore, decellularization protocols that use various detergents and enzymes lead to loss of glycosaminoglycans that serve as a reservoir for growth factors and other potent biologic signals. Ultimately, little is known about the specific effects of any particular decellularization agent on the ECM of a scaffold and the impact of those changes on cell behavior. Residual detergents and other chemicals could also negatively alter the host response to the tissue. In particular, it is unlikely that SDS, which has a high affinity for proteins, is fully rinsed from tissue after decellularization. Also of concern, residual enzymes, such as trypsin or collagenase, may accelerate breakdown of the ECM and hinder cell attachment. Assays are needed to determine whether chemicals used for decellularization have been removed from the scaffold. The development of new decellularization strategies that avoid these chemicals would be even more advantageous.

\section{Cell sourcing to create bioartificial organs}

The lack of an abundant source of human cells is a major limitation to the clinical application of engineered organs for transplantation. Ideally, human cells could be primarily obtained from organs rejected for orthotopic transplantation and, in the case of liver, unused segments from volume-reduced donor livers used for transplantation $(50,51)$.

One potential source of human cells for engineered organs is fetal tissues. It is currently unclear whether fetal cells can be sufficiently expanded for clinical application (52-54) or whether cells derived from fetal tissues before 20 weeks of gestational age, when most elective abortions are performed, would properly differentiate and function. Furthermore, there are serious ethical concerns about the widespread use of these cells in transplantation (55).

Human cells might also be obtained by expansion and differentiation of pluripotent stem cells. While this possibility has generated enthusiasm, realization of this approach in a clinical setting remains in the distant future. However, decellularized organs could be used for stem cell differentiation and expansion. Adult stem cells have been proposed as the primary repair entities for their corresponding organs $(56,57)$. However, difficulties in the culture, expansion, and functional differentiation have limited their use.

Alternatively, pluripotent human ES cells (58) could be an important cell source for cell-based therapies and tissue formation, although identification and purification of specific cell types, sufficient cellular maturation/function, overcoming the immune barrier, and ethical concerns remain the major challenges. Engineering pluripotency of human somatic cells by the ectopic expression of transcription factors (OCT4, SOX2, KLF4, c-MYC, NANOG, and LIN28) has opened the possibility of generating autologous cells for cell/organ replacement therapies $(59,60)$. Induced pluripotent stem (iPS) cells can be propagated indefinitely as undifferentiated cells and can differentiate into practically any cell type like ES cells (61). However, iPS cells and ES cells also share tumorigenic traits. Rapidly accumulating work suggests considerable differences between these two pluripotent cell types. For example, iPS cells are more susceptible to acquired chromosomal aberrations, even more so than ES cells (62-64). This can be a consequence of their somatic cell origin, reprogramming stress, culture adaptation, and aneuploidy (65-67). Thus, accumulating data suggest that the reprogramming process is often accompanied not only by genetic abnormalities, but also by epigenetic alterations, which are expected to increase tumorigenicity $(63,64,68-70)$. 
Moreover, the differentiation potential of ES/iPS cells has been largely shown for many cell types, including endothelial cells (71), cardiomyocytes (72), and hepatocytes (73-75). Recently, considerable variability was reported in the differentiation efficiency among ES/iPS cell lines (76). Beyond the issue of differentiation variability, differentiated cells derived from ES/iPS cells may still be immature, functionally resembling fetal or neonatal phenotype. Cell maturity may prove to be critical for diseases that require differentiated cells (e.g., hepatocytes, dopaminergic neurons) (77-79). Recent studies suggest that direct conversion of somatic cells into specific lineages is possible, suggesting a potential alternative to induce mature phenotypes (80-82).

No matter which stem cell type is used, challenges remain to reliably generate large quantities of well-differentiated cells. The techniques to assemble whole organs in vitro and the procedures to transplant these organs in disease-relevant animal models must be performed using primary mature cells isolated from donors before transplantation with stem cells is attempted to provide enough evidence that whole-organ assembly is feasible.

Repopulation of decellularized organs by host cells in vivo has also been proposed. Surgical mesh materials derived from ECM recruit a myriad of differentiated and progenitor cells to participate in remodeling over time (83-86), and repopulation of tracheal ECM by endogenous vascular cells and epithelium has been shown in clinical cases $(23,87)$. However, to date, there is insufficient support for a similar endogenous cell source repopulating more complex vascularized, decellularized scaffolds in vivo to generate a functional organ $(6,7)$.

\section{Tissue assembly in organ engineering}

Cell-ECM interactions. Cell-ECM interactions are important in regulating complex cell functions, including homing, mobilization, structural support, and signals for self-renewal and differentiation $(14,88)$. The unique microstructure and ultrastructure provide distinct signals for resident cells (89). Organ-specific ECM scaffolds can maintain the phenotype of cells in a differentiated state or drive differentiation of uncommitted cells in vitro (90-92). Thus, organ-specific ECM scaffolds may facilitate a constructive tissue/organ-specific response. For example, liver-specific ECM is more effective at maintaining hepatocytes and sinusoidal endothelial cell differentiation than ECM derived from SIS or UBM (93). Furthermore, lung ECM has been shown to promote differentiation of mouse ES cells into various site-appropriate lung lineages (90). ECM scaffolds also promote differentiation of macrophages toward an antiinflammatory phenotype, consistent with tissue remodeling and accommodation $(84,94)$.

The ECM of organs is comprised of a network of collagens and other structural proteins filled with a hydrogel of proteoglycans. In addition, nonstructural ECM components, such as matricellular proteins, support cell adhesion, migration, proliferation, apoptosis, and differentiation (95). Cumulatively, the ECM controls the bulk mechanical environment and contributes to the microenvironment through presentation of signaling molecules, such as growth factors, cytokines, enzymes, and other diffusible molecules. The presence of heparin sulfate in the matrix allows for storage and release of various chemokines (e.g., transforming growth factor- $\beta$, vascular endothelial cell growth factor, and hepatocyte growth factor) $(96,97)$ and could allow ECM scaffolds to serve as a reservoir for delivery of factors to cells within the matrix in controlled concentrations and gradients. Thus, controlling the composition of the ECM might regulate the fate of cells grown within the organ scaffold.

In addition to signals provided by intact ECM, the degradation products of ECM are also a potent source for cell signaling. In vitro, ECM scaffold degradation products have inherent bioactivity, including antibacterial and chemotactic properties (98-100). In accordance with this observation, in vivo studies showed infection resistance in surgical sites treated with $\operatorname{ECM}(101,102)$, recruitment of progenitor cells to the site of ECM remodeling $(83,103)$, and site-specific remodeling $(83,104)$. Degradation of a biologic scaffold, such as SIS and UBM, is a critical component of the site-appropriate tissue remodeling process $(20,83)$.

In contrast, the objective of whole-organ engineering is to develop a transplantable organ that will remodel slowly over time and resume normal homeostasis. As such, the degradation characteristics of ECM for surgical mesh applications, while potentially desirable from a biological standpoint, would be disastrous from a structural perspective. If engineered organs behave more like inductive scaffolds than transplants, then the degraded scaffold will likely be replaced by dense connective tissue lacking organ structure and functionality (43).

Cell-cell interactions and the complex $3 D$ tissue physiology. Heterogeneous cell-cell contacts appear particularly important for adult, progenitor, and pluripotent stem cells. The development and function of specialized tissue critically depends on the interactions between parenchymal and nonparenchymal cells (15). Although the functional importance of cell-cell interactions is well established in many tissues, the fundamental molecular mechanisms are still unclear $(105,106)$. Research into these cell-cell interactions is further confounded by the diversity of supportive cell types that are found in whole organs. Nearly all cells in the body require cues from a truly $3 \mathrm{D}$ environment to assemble relevant physiological tissue structures that functionally mimic authentic organs, including appropriate cell adhesion, migration, contraction, metabolic function, and differentiation (107-113). Because ECM scaffolds largely retain the $3 \mathrm{D}$ tissue architecture and composition of the tissue from which they are isolated $(23,26,28)$, they can provide the physiological 3D anatomical structures of the native organ, including vascular conduits, which are difficult to manufacture in vitro $(5,9,42,114,115)$. Thus, cocultures in an organ-specific structure allow for greater control over interactions between cell types from the same organ. These techniques could potentially provide new insights on the mechanisms of cell-cell communication, function, and differentiation toward the construction of organs and complex tissue. Additionally, from a structural point of view, the $3 \mathrm{D}$ configuration and the unique stiffness provided in the decellularized organ can dramatically affect integrin-binding ligands and cell fate (116-119).

\section{Translational hurdles}

The major challenge with success of transplantable bioengineered organs will be development of durable vascular networks. As opposed to surgical meshes, which can be revascularized adequately after implantation, the presence of cells within the construct requires an immediate blood supply to maintain cell survival due to the thickness of the tissue and corresponding diffusion distance. The lack of cell survival after implantation has led investigators away from cell seeding in engineered tracheal tissues, in favor of recellularization by host cells in vivo with the addition of stimulating factors (120). 
In engineered organs that retain the vasculature, the issue of restoring blood flow acutely is less challenging, but the question of how long it can be retained remains. ECM is evolutionarily designed to induce coagulation when exposed to blood. Therefore, any incompletely reendothelialized vasculature is at risk for acute thrombosis, leading to localized organ failure. Furthermore, endothelium provides a barrier function that prevents edema within tissues $(24,26)$. Strategies previously used to reduce coagulation in cardiovascular devices may prove useful $(121,122)$.

Another challenge will be replacing all of the functions of the engineered organ. Thus far, systems have used relatively few cell types to restore organ functions, but organs are composed of numerous cell types. An important remaining question is whether the full complement of cell types needs to be replaced in vitro or whether a subset of cells can be derived from the body's resident cells, such as macrophages and other immune cells.

On a more practical level, widespread regulatory approval of these organs will depend on developing standards for acceptable scaffold characteristics, in terms of the amount and type of cellular material retained and chemicals left behind as well as the ECM properties. Considering the experience in engineered tracheal reconstruction, the time for decellularization of the trachea has become a barrier to emergency surgery, so either more rapid decellularization techniques must be developed or storage techniques for decellularized tissues must be enhanced. These concerns will be relevant to engineered organs as well.

Furthermore, if the cells used are anything other than autologous cells, specific criteria will need to be established to determine their safety from disease transmission and immune rejection. A fundamental lack of understanding about how much function must be recapitulated in the engineered organ prior to implantation still exists. For the trachea, a shorter culture time improved results, with most repopulation and function coming after implantation due to factors like erythropoietin and granulocyte colony-stimulating factor that may enhance endogenous stem cell recruitment (120). This paradigm may apply to other engineered organs, though considerable work is necessary to experimentally prove this. Alternatively, strategies that shorten the time to develop mature tissue in culture and technologies that maintain functionality upon implantation may be used.

\section{Conclusion}

The clinical applications of tissue engineering and regenerative medicine have produced a variety of cell- and ECM-based scaffolds, with recent advances in engineering trachea and urinary bladder replacements. The next step for tissue engineering is to address the critical need for bioartificial tissues through the development of vital organs for transplantation. Although the proof of principle of whole-organ assembly and transplantation has been shown for some organs (heart, liver, lungs), the remaining hurdles will ultimately require an interdisciplinary approach to become a clinical reality. Unifying criteria for specific whole-organ decellularization that interrogate measurable parameters are necessary to assure quality control for the scaffold. Scalability and customization of the decellularization process and evaluation criteria will be needed. The organ assembly process requires the systematic delivery of different cell types that will eventually form an appropriate tissue structure. Thus, real-time imaging techniques that can evaluate cell delivery and mobilization of different cell types would benefit the advancement of tissue assembly.
Once the biology of cell communications and the cellular microenvironment are better understood, organ assembly systems could be used to construct artificial organs with similar architecture and functionality to normal organs that can be cultured, grown, and transplanted. The best cell sources remain unknown. Several obstacles must be overcome before the cells generated can be used widely in preclinical studies. Most differentiation protocols have been developed to fit research laboratory experiments, thus significant investment must be made in scaling up protocols to produce sufficient cells to reconstitute a functional human organ. Moreover, most protocols, regardless of the strategies, are inefficient at reproducing all of the desired functions of native cells. However, the organ assembly system might achieve further maturation by allowing cellular and extracellular cues of an organ scaffold to guide formation of a complex tissue. Finally, transplantation of engineered organs has been challenging and limited to hours; thus, systems to guarantee long-term survival of the transplanted organs need to be developed (e.g., anticoagulant molecules). Although these issues remain unsolved for the majority of protocols, it is encouraging to note that cases of transplantation of non-solid organs, such as the engineered trachea, are underway. Auxiliary or heterotopic organ transplant using bioengineered organs may serve as a bridge to transplantation, with an eventual goal of a permanent, durable organ graft as an accepted solution for organ failure.

\section{Acknowledgments}

We acknowledge the support of the NIH (DK083556 to A. Soto-Gutierrez; EB009237 and DC009655 to T.W. Gilbert). This work was also supported by a faculty development grant from the American Society of Transplantation to A. Soto-Gutierrez and the Excellence in Academic Medicine Act through the Illinois Department of Healthcare and Family Services, the Northwestern Memorial Foundation Dixon Translational Research Grants Initiative, a grant from the Zell Family Foundation, the American Association for the Study of Liver Diseases, and the American Liver Foundation Liver Scholar Award to J.A. Wertheim. We also would like to thank Ken Fukumitsu for his critical comments on this manuscript. This work was supported in part by Health Resources and Services Administration contract 234-2005-37011C. The content is the responsibility of the authors alone and does not necessarily reflect the views or policies of the Department of Health and Human Services, nor does mention of trade names, commercial products, or organizations imply endorsement by the US Government.

Address correspondence to: Alejandro Soto-Gutierrez, Department of Pathology, University of Pittsburgh, 3511 Rangos Research Building, 530 45th Street, Pittsburgh, Pennsylvania 15201, USA. Phone: 412.692.5562; Fax: 412.692.6599; E-mail: sotogutierreza@ upmc.edu. Or to: Jason A. Wertheim, Comprehensive Transplant Center, Northwestern University, Arkes Pavilion, Suite 1900, 676 N. St. Clair St., Chicago, Illinois 60611, USA. Phone: 312.695.0257; Fax: 312.695.9194; E-mail: jwerthei@nmh.org. Or to: Harald C. Ott, Department of Surgery, Massachusetts General Hospital, 55 Fruit St., GRB-425, Boston, Massachusetts 02114, USA. Phone: 617.726.2803; Fax: 617.724.3499; E-mail: hott@partners.org. Or to: Thomas W. Gilbert, Research and Development, ACell Inc., 6640 Eli Whitney Drive, Columbia, Maryland 21046, USA. Phone: 410.953.8509; E-mail: thomasgilbert@acell.com.

Thomas W. Gilbert's present address is: ACell Inc., Columbia, Maryland, USA. 
1.2003 Annual Report of the U.S. Organ Procurement and Transplantation Network and the Scientific Registry for Transplant Recipients: Transplant Data 1993-2002. Department of Health and Human Services, Health Resources and Services Administration, Office of Special Programs, Division of Transplantation, Rockville, Maryland, USA; United Network for Organ Sharing, Richmond, Virginia, USA; University Renal Research and Education Association, Ann Arbor, Michigan, USA

2. Organ Procurement and Transplantation Network (OPTN) and Scientific Registry of Transplant Recipients (SRTR). OPTN/SRTR 2010 Annual Data Report. Rockville, Maryland, USA: Department of Health and Human Services, Health Resources and Services Administration, Healthcare Systems Bureau, Division of Transplantation; 2011.

3. Kamath PS, et al. A model to predict survival in patients with end-stage liver disease. Hepatology. 2001;33(2):464-470.

4. Ott HC, et al. Perfusion-decellularized matrix: using nature's platform to engineer a bioartificial heart. Nat Med. 2008;14(2):213-221.

5. Gilbert TW, Sellaro TL, Badylak SF. Decellularization of tissues and organs. Biomaterials. 2006; 27(19):3675-3683.

6. Badylak SF, Taylor D, Uygun K. Whole-organ tissue engineering: decellularization and recellularization of three-dimensional matrix scaffolds. Annu Rev Biomed Eng. 2011;13:27-53.

7. Badylak SF, Weiss DJ, Caplan A, Macchiarini P. Engineered whole organs and complex tissues. Lancet. 2012;379(9819):943-952.

8. Niklason LE, Langer R. Prospects for organ and tissue replacement. JAMA. 2001;285(5):573-576.

9. Schenke-Layland K, Nerem RM. In vitro human tissue models-moving towards personalized regenerative medicine. Adv Drug Deliv Rev. 2011;63(4-5):195-196.

10. Earle WR, Schilling EL, Shannon JE. Growth of animal tissue cells on three-dimensional substrates. J Natl Cancer Inst. 1951;12(1):179-193.

11. Bell E, Ivarsson B, Merrill C. Production of a tissuelike structure by contraction of collagen lattices by human fibroblasts of different proliferative potential in vitro. Proc Natl Acad Sci U S A. 1979; 76(3):1274-1278

12. Meezan E, Hjelle JT, Brendel K, Carlson EC. A simple, versatile, nondisruptive method for the isolation of morphologically and chemically pure basement membranes from several tissues. Life Sci. 1975;17(11):1721-1732.

13. Rojkind M, Gatmaitan Z, Mackensen S, Giambrone MA, Ponce P, Reid LM. Connective tissue biomatrix: its isolation and utilization for long-term cultures of normal rat hepatocytes. J Cell Biol. 1980; 87(1):255-263

14. Bissell MJ, Hall HG, Parry G. How does the extracellular matrix direct gene expression? J Theor Biol. 1982;99(1):31-68.

15. Cunha GR, Bigsby RM, Cooke PS, Sugimura Y. Stromal-epithelial interactions in adult organs. Cell Differ. 1985;17(3):137-148.

16. Lwebuga-Mukasa JS, Ingbar DH, Madri JA. Repopulation of a human alveolar matrix by adult rat type II pneumocytes in vitro. A novel system for type II pneumocyte culture. Exp Cell Res. 1986; 162(2):423-435.

17. Langer R, Vacanti JP. Tissue Eng. Science. 1993; 260(5110):920-926.

18. Naughton GK, Tolbert WR, Grillot TM. Emerging developments in tissue engineering and cell technology. Tissue Eng. 1995;1(2):211-219.

19. Kridel RW, Foda H, Lunde KC. Septal perforation repair with acellular human dermal allograft. Arch Otolaryngol Head Neck Surg. 1998;124:73-78.

20. Badylak SF, Freytes DO, Gilbert TW. Extracellular matrix as a biological scaffold material: Structure and function. Acta Biomater. 2009;5(1):1-13.
21. Atala A, Bauer SB, Soker S, Yoo JJ, Retik AB. Tissueengineered autologous bladders for patients needing cystoplasty. Lancet. 2006;367(9518):1241-1246.

22. Jungebluth $P$, et al. Tracheobronchial transplantation with a stem-cell-seeded bioartificial nanocomposite: a proof-of-concept study. Lancet. 2011; 378(9808):1997-2004.

23. Macchiarini $P$, et al. Clinical transplantation of a tissue-engineered airway. Lancet. 2008; 372(9655):2023-2030.

24. Ott HC, et al. Regeneration and orthotopic transplantation of a bioartificial lung. Nat Med. 2010; 16(8):927-933.

25. Uygun BE, et al. Organ reengineering through development of a transplantable recellularized liver graft using decellularized liver matrix. Nat Med. 2010;16(7):814-820.

26. Petersen TH, et al. Tissue-engineered lungs for in vivo implantation. Science. 2010;329(5991):538-541.

27. Song JJ, et al. Enhanced in vivo function of bioartificial lungs in rats. Ann Thorac Surg. 2011; 92(3):998-1005.

28. Soto-Gutierrez A, et al. A whole-organ regenerative medicine approach for liver replacement. Tissue Eng Part C Methods. 2011;17(6):677-686.

29. Baptista PM, Siddiqui MM, Lozier G, Rodriguez SR, Atala A, Soker S. The use of whole organ decellularization for the generation of a vascularized liver organoid. Hepatology. 2011;53(2):604-617.

30. Wainwright JM, et al. Preparation of cardiac extracellular matrix from an intact porcine heart. Tissue Eng Part C Methods. 2010;16(3):525-532.

31. Nakayama KH, Batchelder CA, Lee CI, Tarantal AF. Decellularized rhesus monkey kidney as a three-dimensional scaffold for renal tissue engineering. Tissue Eng Part A. 2010;16(7):2207-2216.

32. Barakat $O$, et al. Use of decellularized porcine liver for engineering humanized liver organ. J Surg Res. 2012;173(1):e11-e25.

33. Klein AS, Messersmith EE, Ratner LE, Kochik R, Baliga PK, Ojo AO. Organ donation and utilization in the United States, 1999-2008. Am J Transplant. 2010;10(4 pt 2):973-986.

34. Murphy SL, Xu JQ, Kochanek KD. Deaths: Preliminary data for 2010. In: National Vital Statistics Reports. Vol. 60, No. 4. Hyattsville, Maryland, USA: National Center for Health Statistics; 2012.

35. Tomita Y, Nihira M, Ohno Y, Sato S. Ultrastructural changes during in situ early postmortem autolysis in kidney, pancreas, liver, heart and skeletal muscle of rats. Leg Med (Tokyo). 2004;6(1):25-31.

36. McPherson TB, Liang H, Record RD, Badylak SF. Galalpha $(1,3)$ Gal epitope in porcine small intestinal submucosa. Tissue Eng. 2000;6(3):233-239.

37. Daly KA, et al. Effect of the alphaGal epitope on the response to small intestinal submucosa extracellular matrix in a nonhuman primate model. Tissue Eng Part A. 2009;15(12):3877-3888.

38. Stone KR, Ayala G, Goldstein J, Hurst R, Walgenbach A, Galili U. Porcine cartilage transplants in the cynomolgus monkey. III. Transplantation of alpha-galactosidase-treated porcine cartilage. Transplantation. 1998;65:1577-1583.

39. Xu H, et al. A porcine-derived acellular dermal scaffold that supports soft tissue regeneration: removal of terminal galactose-alpha-(1,3)-galactose and retention of matrix structure. Tissue Eng Part A. 2009; 15(7):1807-1819.

40. Lila N, McGregor CG, Carpentier S, Rancic J, Byrne GW, Carpentier A. Gal knockout pig pericardium: new source of material for heart valve bioprostheses. J Heart Lung Transplant. 2010;29(5):538-543.

41. Baiguera $S$, et al. Long-term changes to in vitro preserved bioengineered human trachea and their implications for decellularized tissues. Biomaterials. 2012;33(14):3662-3672

42. Crapo PM, Gilbert TW, Badylak SF. An overview of tissue and whole organ decellularization processes.
Biomaterials. 2011;32(12):3233-3243.

43. Gilbert TW. Strategies for tissue and organ decellularization. J Cell Biochem. 2012;113(7):2217-2222.

44. Keane TJ, Londono R, Turner NJ, Badylak SF. Consequences of ineffective decellularization of biologic scaffolds on the host response. Biomaterials. 2012;33(6):1771-1781.

45. Gilbert TW, Freund JM, Badylak SF. Quantification of DNA in biologic scaffold materials. J Surg Res. 2009;152(1):135-139.

46. Wallis JM, et al. Comparative assessment of detergent-based protocols for mouse lung de-cellularization and re-cellularization. Tissue Eng Part C Methods. 2012;18(6):420-432.

47. Daly $\mathrm{AB}$, et al. Initial binding and recellularization of decellularized mouse lung scaffolds with bone marrow-derived mesenchymal stromal cells. Tissue Eng Part A. 2012;18(1-2):1-16.

48. Discher DE, Mooney DJ, Zandstra PW. Growth factors, matrices, and forces combine and control stem cells. Science. 2009;324(5935):1673-1677.

49. Miroshnikova YA, Jorgens DM, Spirio L, Auer M, Sarang-Sieminski AL, Weaver VM. Engineering strategies to recapitulate epithelial morphogenesis within synthetic three-dimensional extracellular matrix with tunable mechanical properties. Phys Biol. 2011;8(2):026013.

50. Mitry RR, et al. One liver, three recipients: segment IV from split-liver procedures as a source of hepatocytes for cell transplantation. Transplantation. 2004;77(10):1614-1616.

51. Rady MY, Verheijde JL, McGregor J. Organ procurement after cardiocirculatory death: a critical analysis. J Intensive Care Med. 2008;23(5):303-312.

52. Oertel M. Fetal liver cell transplantation as a potential alternative to whole liver transplantation? J Gastroenterol. 2011;46(8):953-965.

53. Shaw SW, David AL, De Coppi P. Clinical applications of prenatal and postnatal therapy using stem cells retrieved from amniotic fluid. Curr Opin Obstet Gynecol. 2011;23(2):109-116.

54. Sipos PI, Crocker IP, Hubel CA, Baker PN. Endothelial progenitor cells: their potential in the placental vasculature and related complications. Placenta. 2010;31(1):1-10.

55. Childress JF. Ethics, public policy, and human fetal tissue transplantation research. Kennedy Inst Ethics J. 1991;1(2):93-121.

56. Park D, et al. Endogenous bone marrow MSCs are dynamic, fate-restricted participants in bone maintenance and regeneration. Cell Stem Cell. 2012; 10(3):259-272.

57. Alison MR, Islam S. Attributes of adult stem cells. J Pathol. 2009;217(2):144-160.

58. Ludwig TE, et al. Derivation of human embryonic stem cells in defined conditions. Nat Biotechnol. 2006;24(2):185-187.

59. Takahashi K, et al. Induction of pluripotent stem cells from adult human fibroblasts by defined factors. Cell. 2007;131(5):861-872.

60. Yu J, et al. Induced pluripotent stem cell lines derived from human somatic cells. Science. 2007; 318(5858):1917-1920.

61. Robinton DA, Daley GQ. The promise of induced pluripotent stem cells in research and therapy. Nature. 2012;481(7381):295-305.

62. Wu SM, Hochedlinger K. Harnessing the potential of induced pluripotent stem cells for regenerative medicine. Nat Cell Biol. 2011;13(5):497-505.

63. Puri MC, Nagy A. Concise review: Embryonic stem cells versus induced pluripotent stem cells: the game is on. Stem Cells. 2012;30(1):10-14.

64. Ben-David U, Benvenisty N. The tumorigenicity of human embryonic and induced pluripotent stem cells. Nat Rev Cancer. 2011;11(4):268-277.

65. Chin $\mathrm{MH}$, et al. Induced pluripotent stem cells and embryonic stem cells are distinguished by gene expression signatures. Cell Stem Cell. 2009; 
5(1):111-123.

66. Guenther MG, et al. Chromatin structure and gene expression programs of human embryonic and induced pluripotent stem cells. Cell Stem Cell. 2010; 7(2):249-257.

67. Chin MH, Pellegrini M, Plath K, Lowry WE. Molecular analyses of human induced pluripotent stem cells and embryonic stem cells. Cell Stem Cell. 2010;7(2):263-269.

68. Malchenko S, et al. Cancer hallmarks in induced pluripotent cells: new insights. J Cell Physiol. 2010; 225(2):390-393.

69. Ohm JE, et al. Cancer-related epigenome changes associated with reprogramming to induced pluripotent stem cells. Cancer Res. 2010;70(19):7662-7673.

70. Narsinh KH, et al. Single cell transcriptional profiling reveals heterogeneity of human induced pluripotent stem cells. J Clin Invest. 2011;121(3):1217-1221.

71. Wang ZZ, et al. Endothelial cells derived from human embryonic stem cells form durable blood vessels in vivo. Nat Biotechnol. 2007;25(3):317-318.

72. Dubois NC, et al. SIRPA is a specific cell-surface marker for isolating cardiomyocytes derived from human pluripotent stem cells. Nat Biotechnol. 2011; 29(11):1011-1018.

73. Basma H, et al. Differentiation and transplantation of human embryonic stem cell-derived hepatocytes. Gastroenterology. 2009;136(3):990-999.

74. Si-Tayeb K, et al. Highly efficient generation of human hepatocyte-like cells from induced pluripotent stem cells. Hepatology. 2010;51(1):297-305.

75. Soto-Gutierrez A, et al. Reversal of mouse hepatic failure using an implanted liver-assist device containing ES cell-derived hepatocytes. Nat Biotechnol. 2006;24(11):1412-1419.

76. Osafune $\mathrm{K}$, et al. Marked differences in differentiation propensity among human embryonic stem cell lines. Nat Biotechnol. 2008;26(3):313-315.

77. Soltys KA, et al. Barriers to the successful treatment of liver disease by hepatocyte transplantation. J Hepatol. 2010;53(4):769-774.

78. Kriks S, et al. Dopamine neurons derived from human ES cells efficiently engraft in animal models of Parkinson's disease. Nature. 2011;480(7378):547-551.

79. Fox IJ, et al. Treatment of the Crigler-Najjar syndrome type I with hepatocyte transplantation. NEngl J Med. 1998;338(20):1422-1426.

80. Ieda $M$, et al. Direct reprogramming of fibroblasts into functional cardiomyocytes by defined factors. Cell. 2010;142(3):375-386.

81. Chambers SM, Studer L. Cell fate plug and play: direct reprogramming and induced pluripotency. Cell. 2011;145(6):827-830.

82. Huang $P$, et al. Induction of functional hepatocyte-like cells from mouse fibroblasts by defined factors. Nature. 2011;475(7356):386-389.

83. Agrawal V, et al. Epimorphic regeneration approach to tissue replacement in adult mammals. Proc Natl Acad SciU S A. 2010;107(8):3351-3355.

84. Badylak SF, Gilbert TW. Immune response to biologic scaffold materials. Semin Immunol. 2008; 20(2):109-116.

85. Badylak SF, Kokini K, Tullius B, Simmons-Byrd A, Morff R. Morphologic study of small intestinal submucosa as a body wall repair device. J Surg Res. 2002;103(2):190-202.

86. Gilbert TW, Stewart-Akers AM, Simmons-Byrd A, Badylak SF. Degradation and remodeling of small intestinal submucosa in canine Achilles tendon repair. J Bone Joint Surg Am. 2007;89(3):621-630.

87. Go T, et al. Both epithelial cells and mesenchymal stem cell-derived chondrocytes contribute to the survival of tissue-engineered airway transplants in pigs. J Thorac Cardiovasc Surg. 2010;139(2):437-443.

88. Nelson CM, Bissell MJ. Of extracellular matrix, scaffolds, and signaling: tissue architecture regulates development, homeostasis, and cancer. Annu Rev Cell Dev Biol. 2006;22:287-309.

89. Brown BN, et al. Surface characterization of extracellular matrix scaffolds. Biomaterials. 2010; 31(3):428-437.

90. Cortiella J, et al. Influence of acellular natural lung matrix on murine embryonic stem cell differentiation and tissue formation. Tissue Eng Part A. 2010; 16(8):2565-2580

91. Sellaro TL, Ravindra AK, Stolz DB, Badylak SF. Maintenance of hepatic sinusoidal endothelial cell phenotype in vitro using organ-specific extracellular matrix scaffolds. Tissue Eng. 2007;13(9):2301-2310.

92. Wang Y, et al. Lineage restriction of human hepatic stem cells to mature fates is made efficient by tissue-specific biomatrix scaffolds. Hepatology. 2011; 53(1):293-305.

93. Sellaro TL, et al. Maintenance of human hepatocyte function in vitro by liver-derived extracellular matrix gels. Tissue Eng Part A. 2010;16(3):1075-1082.

94. Brown BN, Ratner BD, Goodman SB, Amar S, Badylak SF. Macrophage polarization: An opportunity for improved outcomes in biomaterials and regenerative medicine. Biomaterials. 2012;33(15):3792-3802.

95. Jun JI, Lau LF. Taking aim at the extracellular matrix: CCN proteins as emerging therapeutic targets. Nat Rev Drug Discov. 2011;10(12):945-963.

96. Tschumperlin DJ, et al. Mechanotransduction through growth-factor shedding into the extracellular space. Nature. 2004;429(6987):83-86.

97. Paralkar VM, Vukicevic S, Reddi AH. Transforming growth factor beta type 1 binds to collagen IV of basement membrane matrix: implications for development. Dev Biol. 1991;143(2):303-308.

98. Brennan EP, Reing J, Chew D, Myers-Irvin JM, Young EJ, Badylak SF. Antibacterial activity within degradation products of biological scaffolds composed of extracellular matrix. Tissue Eng. 2006; 12(10):2949-2955.

99. Li F, Li W, Johnson S, Ingram D, Yoder M, Badylak SF. Low-molecular-weight peptides derived from extracellular matrix as chemoattractants for primary endothelial cells. Endothelium. 2004;11(3-4):199-206.

100.Sarikaya A, Record R, Wu CC, Tullius B, Badylak SF, Ladisch M. Antimicrobial activity associated with extracellular matrices. Tissue Eng. 2002; 8(1):63-71.

101. Badylak SF, Wu CC, Bible M, McPherson E. Host protection against deliberate bacterial contamination of an extracellular matrix bioscaffold versus Dacron mesh in a dog model of orthopedic soft tissue repair. J Biomed Mater Res B Appl Biomater. 2003;67(1):648-654.

102. Shell DH 4th, Croce MA, Cagiannos C, Jernigan TW, Edwards N, Fabian TC. Comparison of small-intestinal submucosa and expanded polytetrafluoroethylene as a vascular conduit in the presence of gram-positive contamination. Ann Surg. 2005;241(6):995-1001.

103.Zantop T, Gilbert TW, Yoder MC, Badylak SF. Extracellular matrix scaffolds are repopulated by bone marrow-derived cells in a mouse model of Achilles tendon reconstruction. J Orthop Res. 2006;24(6):1299-1309.

104. Manni ML, Czajka CA, Oury TD, Gilbert TW. Extracellular matrix powder protects against bleomycin-induced pulmonary fibrosis. Tissue Eng Part A. 2011;17(21-22):2795-2804.

105.Soto-Gutierrez A, et al. Differentiation of mouse embryonic stem cells to hepatocyte-like cells by co-culture with human liver nonparenchymal cell lines. Nat Protoc. 2007;2(2):347-356.

106.Jindal R, Nahmias Y, Tilles AW, Berthiaume F, Yarmush ML. Amino acid-mediated heterotypic interaction governs performance of a hepatic tissue model. FASEB J. 2009;23(7):2288-2298.

107. Roskelley CD, Desprez PY, Bissell MJ. Extracellular matrix-dependent tissue-specific gene expression in mammary epithelial cells requires both physical and biochemical signal transduction. Proc Natl Acad SciUS A. 1994;91(26):12378-12382.

108.Bissell MJ, Rizki A, Mian IS. Tissue architecture: the ultimate regulator of breast epithelial function. Curr Opin Cell Biol. 2003;15(6):753-762.

109. Wozniak MA, Desai R, Solski PA, Der CJ, Keely PJ. ROCK-generated contractility regulates breast epithelial cell differentiation in response to the physical properties of a three-dimensional collagen matrix. J Cell Biol. 2003;163(3):583-595.

110.Gomez-Lechon MJ, et al. Long-term expression of differentiated functions in hepatocytes cultured in three-dimensional collagen matrix. J Cell Physiol. 1998;177(4):553-562.

111. Rana B, Mischoulon D, Xie Y, Bucher NL, Farmer SR. Cell-extracellular matrix interactions can regulate the switch between growth and differentiation in rat hepatocytes: reciprocal expression of C/EBP alpha and immediate-early growth response transcription factors. Mol Cell Biol. 1994;14(9):5858-5869.

112. Griffith LG, Swartz MA. Capturing complex 3D tissue physiology in vitro. Nat Rev Mol Cell Biol. 2006; 7(3):211-224.

113.Suuronen EJ, Sheardown H, Newman KD, McLaughlin CR, Griffith M. Building in vitro models of organs. Int Rev Cytol. 2005;244:137-173.

114.Zhang S. Fabrication of novel biomaterials through molecular self-assembly. Nat Biotechnol. 2003; 21(10):1171-1178.

115.Soto-Gutierrez A, et al. Cell delivery: from cell transplantation to organ engineering. Cell Transplant. 2010;19(6):655-665.

116. Huebsch $\mathrm{N}$, et al. Harnessing traction-mediated manipulation of the cell/matrix interface to control stem-cell fate. Nat Mater. 2010;9(6):518-526.

117. Peyton SR, Putnam AJ. Extracellular matrix rigidity governs smooth muscle cell motility in a biphasic fashion. J Cell Physiol. 2005;204(1):198-209.

118. Lo CM, Wang HB, Dembo M, Wang YL. Cell movement is guided by the rigidity of the substrate. Biophys J. 2000;79(1):144-152

119. Lutolf MP, et al. Synthetic matrix metalloproteinase-sensitive hydrogels for the conduction of tissue regeneration: engineering cell-invasion characteristics. Proc Natl Acad Sci U S A. 2003;100(9):5413-5418.

120. Jungebluth $\mathrm{P}$, et al. The concept of in vivo airway tissue engineering. Biomaterials. 2012;33(17):4319-4326.

121.Jordan SW, Chaikof EL. Novel thromboresistant materials. JVasc Surg. 2007;45(suppl A):A104-A115.

122. Sin DC, Kei HL, Miao X. Surface coatings for ventricular assist devices. Expert Rev Med Devices. 2009;6(1):51-60. 